\title{
The Diabetes Intention, Attitude, and Behavior Questionnaire: evaluation of a brief questionnaire to measure physical activity, dietary control, maintenance of a healthy weight, and psychological antecedents
}

This article was published in the following Dove Press journal:

Patient Preference and Adherence

29 February 2016

Number of times this article has been viewed

\author{
Shana B Traina' \\ Susan D Mathias \\ Hilary H Colwell ${ }^{2}$ \\ Ross D Crosby ${ }^{2-4}$ \\ Charles Abraham ${ }^{5}$ \\ 'Patient-Reported Outcomes, \\ Janssen Global Services, LLC, \\ Raritan, NJ, USA; ${ }^{2}$ Health Outcomes \\ Solutions, Winter Park, FL, USA; \\ ${ }^{3}$ Biomedical Statistics \& Methodology, \\ Neuropsychiatric Research Institute, \\ Fargo, ND, USA; ${ }^{4}$ Department of \\ Clinical Neuroscience, University of \\ North Dakota School of Medicine and \\ Health Sciences, Grand Forks, ND, \\ USA; ${ }^{5}$ Psychology Applied to Health, \\ University of Exeter Medical School, \\ Exeter, UK
}

Background: This study assessed measurement properties of the 17-item Diabetes Intention, Attitude, and Behavior Questionnaire (DIAB-Q), which measures intention to engage in self-care behaviors, including following a diabetes diet and engaging in appropriate physical activity.

Methods: The DIAB-Q includes questions based on the Theory of Planned Behavior. Items were developed using published literature, input from health care professionals, and qualitative research findings in patients with and without type 2 diabetes mellitus (T2DM). In Stage I of the study, 23 adults with T2DM were interviewed to evaluate the content and clarity of the DIAB-Q. In Stage II 1,015 individuals with T2DM completed the DIAB-Q and supplemental questionnaires, including the Short Form-36 acute (SF-36), section III of the Multidimensional Diabetes Questionnaire, the Summary of Diabetes Self-Care Activities questionnaire, and selfadministered items relevant to the treatment and management of T2DM (eg, blood pressure and glycated hemoglobin $\left[\mathrm{HbA}_{1 \mathrm{c}}\right]$ ) at baseline and 3-7 days later. Once the DIAB-Q scale structure was determined, its test-retest reliability, construct validity, and known-groups validity were evaluated, and minimal clinically important change was estimated.

Results: In Stage I, the 23 respondents surveyed generally reported that the DIAB-Q was clear and comprehensive and endorsed questions as relevant to their intentions to engage in diabetesrelated self-care activities. Most subjects in Stage II were male, Caucasian, and married. Mean age was 63 years. Factor analysis revealed six psychological constructs (Behavior, Planning, Intention, Perceived Behavioral Control, Attitude, and Subjective Norm). Test-retest reliability was acceptable $(\geq 0.70$ ) for all scales, except Perceived Behavioral Control. Construct validity was demonstrated based on correlations with diabetes-specific items/scales and the SF-36. Known-groups validity was confirmed for Behavior, Planning, and Intention when respondents were categorized into groups that differed based on body mass index, disease severity, and $\mathrm{HbA}_{1 \mathrm{c}}$. Item scores were transformed to a 100-point scale, and minimal clinically important change estimates ranged from 6-11 points, representing the change that would be considered important to a respondent.

Conclusion: The DIAB-Q is a brief, psychometrically sound, patient-reported outcome that can be used among individuals with T2DM to evaluate intention to engage in self-care behaviors.

Keywords: diabetes, Theory of Planned Behavior, DIAB-Q, attitude, intention, behavior, patient-reported outcome, questionnaire 


\section{Background}

The 2012 joint position statement from the American Diabetes Association and European Association for the Study of Diabetes for the management of hyperglycemia in type 2 diabetes mellitus (T2DM) recommends a patient-centered approach, whereby the decision-making process involves consideration for the attitudes, preferences, and expectations of each patient to individualize treatment. ${ }^{1}$ To encourage patient adherence to pharmacologic therapies and healthy behaviors that promote achievement of glycemic goals, it is suggested that everyone with T2DM receives standardized general diabetes education, with a focus on dietary interventions and physical activity to promote weight loss or weight maintenance. Pharmacologic therapy should aim to reduce glycated hemoglobin $\left(\mathrm{HbA}_{1 \mathrm{c}}\right)$ levels $<7.0 \%$ for most patients to prevent the development of T2DM-related complications, although the $\mathrm{HbA}_{1 \mathrm{c}}$ target should be individualized based on each patient's characteristics. ${ }^{1}$

There is value in predicting which individuals with T2DM are likely to consistently perform self-care behaviors (eg, dietary and physical activity behaviors), as increasing these behaviors may lead to better outcomes. ${ }^{2}$ Individuals motivated to follow a diabetes self-care regimen are able to overcome barriers (eg, access to healthy foods); are successful in achieving outcomes, such as weight loss, lower blood pressure, or consistent control of $\mathrm{HbA}_{1 \mathrm{c}}$; and may be more likely to adhere to healthy lifestyle changes. ${ }^{3}$ When individuals with T2DM experience noticeable benefits that are meaningful and important to them, they may be motivated to increase the frequency with which they engage in healthy self-care behaviors. ${ }^{4}$ Continuing to engage in healthy behaviors can lead to further benefits, which will in turn reinforce healthy behaviors, and ultimately lead to better outcomes. ${ }^{5}$

As part of the planning for Phase III clinical trials of a novel antihyperglycemic agent, several questionnaires were selected to explore end points that would account for the central role of patient behaviors with respect to T2DM outcomes. Numerous conceptual models were identified that assess modifiable beliefs, attitudes, and intentions that affect the likelihood that individuals will undertake health-related actions. ${ }^{6,7}$ However, there was no disease-specific measure available that was relevant for use among individuals with T2DM. Such a measure of intentions and determinants of intentions would be valuable for applied research and in the clinical trial setting. Therefore, we initiated a process to develop a brief, but psychometrically sound, tool to measure such cognitions based on research showing that adding selfreported measures of attitudes and intentions can increase the capacity of models to predict health behaviors. ${ }^{89}$ This measure, called the Diabetes Intention, Attitude, and Behavior Questionnaire (DIAB-Q), was developed as an instrument to evaluate key T2DM self-care behaviors (Supplementary material). The DIAB-Q was designed to assess five psychological constructs related to physical activity, dietary behavior, and weight loss, as well as assessing the following current behavior patterns: 1) Subjective Norm (ie, social pressure that results from perceived expectations of family, friends, and health care professionals), 2) Attitude, 3) Perceived Behavioral Control (PBC), 4) Intention, 5) Planning, and 6) Behavior (Figure 1). ${ }^{10}$

The objectives of the current study were to assess the content and clarity of the draft DIAB-Q for use with adults with T2DM and to evaluate its scale structure and measurement properties, including test-retest reliability, convergent validity, and known-groups validity, as well as provide an estimate of the minimal clinically important change (MCIC).

\section{Methods DIAB-Q development}

Consideration and evaluation of available cognition models revealed that the Theory of Planned Behavior (TPB) ${ }^{11}$ has been most widely applied and that meta-analytic reviews have indicated that the TPB is better able to predict physical activity and dietary behaviors than other models. ${ }^{12,13}$ In addition, Ajzen has provided clear guidelines for the use of the TBP in predictive studies..$^{10}$ The TPB represents behavior as following directly from intentions, but not all intentions are enacted, and changing intentions does not necessarily result in changed behavior. ${ }^{14}$ Various studies suggest that planning may enhance enactment of intentions. ${ }^{8}, 15$

The DIAB-Q was developed using TPB question stems ${ }^{10}$ to measure self-care behaviors of specific importance for individuals with T2DM. Each item of the DIAB-Q was drafted based on information from various literature sources and input from health care professionals and patients. Patient input was obtained from qualitative research performed in people with and without T2DM to understand their attitudes toward behaviors, such as weight loss and physical activity, and as part of exit interviews conducted at the completion of a Phase II clinical study in individuals with T2DM. ${ }^{16}$ The literature used was based on recognized best practices in the development of patient-reported outcome measures. Validated instruments were also used as a guide in the development of content relevant to self-care behaviors that are important for patients with T2DM, including the Summary of Diabetes Self-Care Activities (SDSCA), ${ }^{17}$ the Short Form-36 version 2 acute (SF-36) questionnaire, ${ }^{18}$ and Multidimensional Diabetes Questionnaire (MDQ) ${ }^{19}$ 

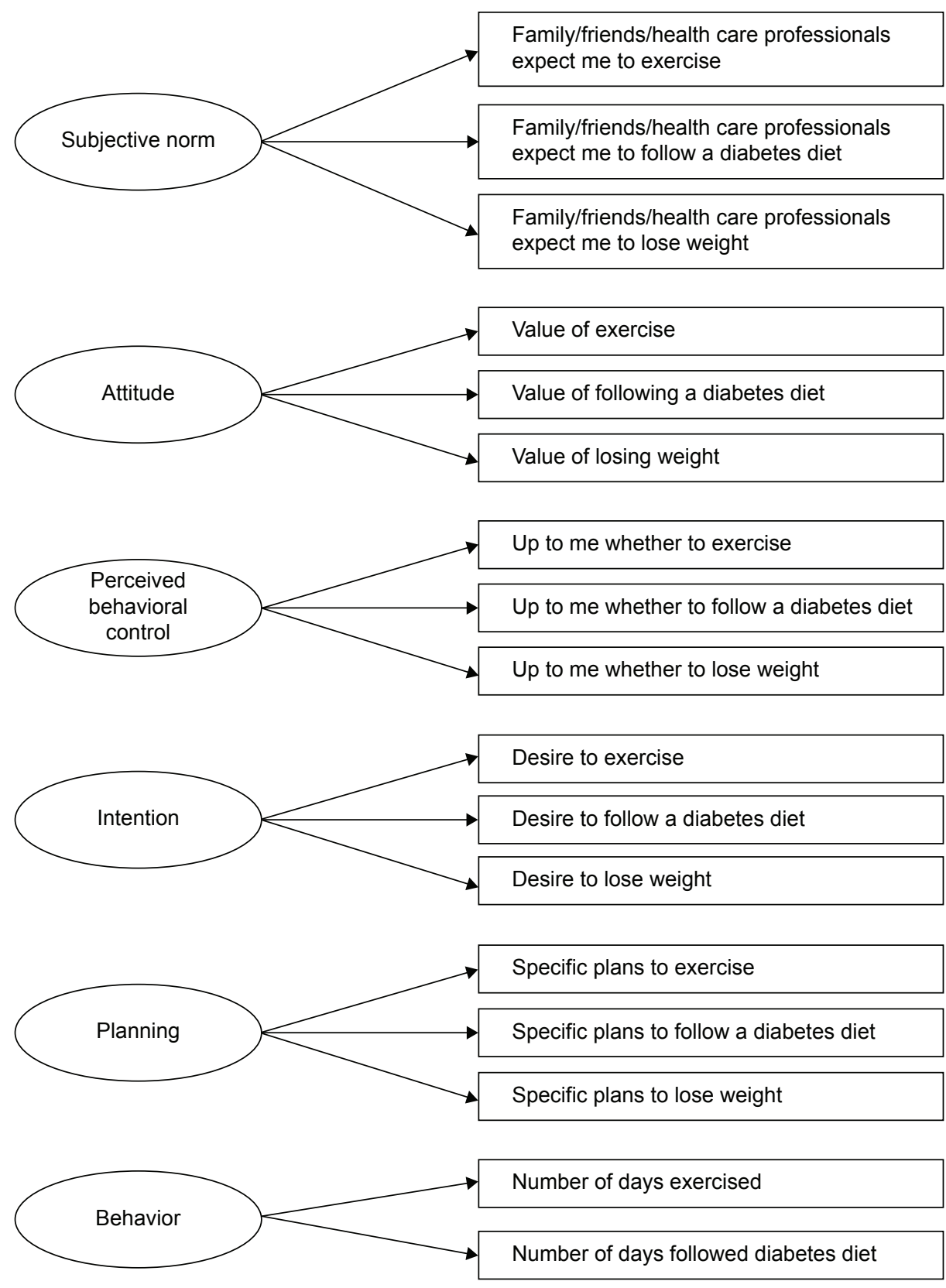

Figure I Conceptual framework of DIAB-Q.

Abbreviation: DIAB-Q, Diabetes Intention, Attitude, and Behavior Questionnaire.

\section{DIAB-Q assessments}

This research was conducted in two stages. First, in-depth interviews were undertaken with a small sample of adults with T2DM to confirm the appropriateness of the content and clarity of a draft version of the DIAB-Q. Then, a larger group of individuals with T2DM completed an online version of the DIAB-Q to provide quantitative data to be used to evaluate its scale structure and measurement properties. Both stages of the study received institutional review board approval, and all respondents provided written informed consent.

\section{Study population}

Participants were recruited by Harris Interactive from their proprietary Chronic Illness Panel, eRewards, and Toluna databases. To be eligible, participants (via self-report) should be $\geq 18$ years old, diagnosed with T2DM and taking a T2DM medication, and have a body mass index (BMI) of 20 to $\leq 45 \mathrm{~kg} / \mathrm{m}^{2}$. If the participant had been diagnosed with anxiety or depression, there could be no dosage change in anxiety/depression medications in the past 3 months. Participants were excluded if they had been diagnosed with type 1 
diabetes mellitus, major depressive disorder, a personality disorder, or an eating disorder in the past 3 months; were currently taking antipsychotics; were currently pregnant or pregnant within the prior 12 months; or had a previous or scheduled gastric bypass surgery, lap band, or liposuction.

\section{Study procedures - qualitative research (Stage I)}

Respondents were contacted by telephone and screened for eligibility. If eligible, in-person interviews were conducted in the first round, followed by telephone interviews. Cognitive interviews were conducted using an iterative process. Respondents were recruited in blocks of six to eight participants. After each block of respondents was interviewed, the moderator and the research team met to discuss what new data had been mentioned by the block of respondents to determine whether revisions to the study materials (eg, interview guide) were needed. All interviews were conducted using semi-structured questions to guide the interview, including questions on each respondent's general understanding of the DIAB-Q items/instructions and relevance of items and time frame. Specifically, the interview started with an introduction on the research process and purpose of the interview, a statement of confidentiality, and a review of the respondent's health conditions. Participants were then asked to review the DIAB-Q and provide their feedback in terms of its understandability, clarity of items, and interpretation of item wording (eg, What type of exercise did you think of when you read the question? Did you have difficulty remembering your activities or motivation in the last 7 days? Have you ever followed a diabetes diet? etc). Interviews lasted 50-60 minutes and were transcribed and coded for analysis. Respondents were remunerated for their time (\$85.00 USD for in-person interviews and $\$ 75.00$ for telephone interviews).

Analysis of data from Stage I was based on coding of interview transcripts. Initial reports were provided by moderators and then, based on the findings from the first round of interviews, interviewers developed codes for specific questions and iteratively applied these codes to analyze results from all of the interviews. Final results were tallied and tabulated.

\section{Study procedures - online questionnaire (Stage II)}

Potential respondents identified by Harris Interactive were emailed an invitation with a link to the online screener. The individuals who participated in Stage I were not eligible to participate in Stage II. If eligible, respondents completed an online questionnaire, including the DIAB-Q, the SF-36, ${ }^{18}$ section III of the MDQ,${ }^{19}$ the SDSCA questionnaire, ${ }^{17}$ items relevant to the treatment and management of T2DM (eg, whether they know their blood pressure or $\left.\mathrm{HbA}_{1 \mathrm{c}}\right)$, and background demographic items.

To assess test-retest reliability, 3-7 days after completing the first questionnaire, all respondents were asked to complete the DIAB-Q again. The 3- to 7-day interval was selected to be short enough not to anticipate clinical changes and to be within the 1-week recall period of the DIAB-Q. To ensure that these analyses only included individuals who did not experience a change in health status between the initial and the follow-up administration of the DIAB-Q, respondents were asked whether they had a routine doctor's appointment, were sick, had to go to the hospital, were diagnosed with an illness, had a change in diabetes or other medication, or lost or gained $\geq 3$ pounds between the time of the initial and follow-up survey.

\section{DIAB-Q scoring}

The DIAB-Q includes 17 items covering six psychological constructs: Subjective Norm (items 5, 11, and 16), Attitude (items 4, 10, and 15), PBC (items 6, 12, and 17), Intention (items 2, 8, and 13), Planning (items 3, 9, and 14), and Behavior (items 1 and 7). The recall period is the past week, and responses are rated on seven-point scales (eg, "strongly disagree" to "strongly agree" or "not at all valuable" to "extremely valuable"). Raw scores are calculated as the sum of the individual item scores. Scores are then transformed to a 0-100 scale, with higher scores indicating higher levels of engagement in beneficial behaviors. For example, higher Planning scores indicate a higher likelihood to plan to engage in self-care.

\section{Statistical methods}

Confirmatory factor analysis (CFA) was conducted to evaluate the conceptual model using data from the initial online questionnaire sample $(n=1,015)$. Model fit was evaluated based on recommended standards: ${ }^{20}$ comparative fit index (CFI; criteria $>0.900)$, Tucker-Lewis index (TLI; criteria $>0.900)$, root mean square error of approximation (RMSEA; criteria $<0.060$ ), and standardized root mean square residual (SRMR; criteria $<0.080$ ). Modification indices were used to improve the overall fit of the model. CFAs were conducted using Mplus Version 6.11. ${ }^{21}$ All additional analyses were conducted with SPSS Version 19.0.0 using the initial online questionnaire sample. 
Floor and ceiling effects were considered to be present if $>15 \%$ of respondents had either the lowest ( 0$)$ or the highest (100) scale score. ${ }^{22}$

Internal consistency reliability was calculated using Cronbach's alpha for all scales. ${ }^{23}$ Test-retest reliability was evaluated using the intraclass correlation coefficient (ICC), with $\geq 0.70$ considered acceptable. ${ }^{24}$ Test-retest analyses were restricted to respondents who indicated no change in health status during the 3- to 7-day period between the initial and the follow-up questionnaires and excluded 289 respondents who reported at least one healthrelated change, including that they had a routine doctor's appointment ( $\mathrm{n}=144)$, lost $\geq 3$ pounds ( $\mathrm{n}=141$ ), had been sick $(n=46)$, had a change to medication other than diabetes medication $(n=42)$, gained $\geq 3$ pounds $(n=23)$, were diagnosed with an illness $(\mathrm{n}=21)$, had a change in diabetes medication $(n=20)$, or had to go to the hospital $(n=12)$ during this time period.

Convergent and divergent validities were evaluated by calculating Pearson's correlation coefficients for DIAB-Q constructs, items from the SDSCA and MDQ, and SF-36 component scores based on the results of the initial surveys and follow-up surveys that were conducted 1 year later.

Known-groups validity analyses were conducted to determine whether the DIAB-Q was able to distinguish between people known to differ based on self-reported clinical factors. Respondents were categorized based on BMI categories (based on self-reported weight and height; $<25,25-29.9,30-39.9$, and $\left.\geq 40 \mathrm{~kg} / \mathrm{m}^{2}\right),{ }^{25}$ most recent self-reported $\mathrm{HbA}_{1 \mathrm{c}}$ level (respondents could choose from $\mathrm{HbA}_{1 \mathrm{c}}$ options of $\leq 6.0 \%, 6.1 \%-6.5 \%, 6.6 \%-7.0 \%$, $7.1 \%-7.5 \%, 7.6 \%-8.0 \%$, and $>8.0 \%$ ), and self-rated diabetes severity ("mild", "moderate", and "severe"). Analysis of variance was conducted to compare BMI, $\mathrm{HbA}_{1 \mathrm{c}}$, and disease severity groups on DIAB-Q scores. Pairwise comparisons between groups were based on Tukey's b post hoc tests, ${ }^{26}$ which controls alpha levels for multiple comparisons.

The MCIC was estimated using a distribution-based approach using three methods: 1 standard error of measurement, 0.5 standardized effect size, and 0.5 responsiveness statistic. Although all three values were considered in establishing the MCIC, greater weight was given to the standard error of measurement because of its relevance to measurement precision. ${ }^{27}$ Respondents were categorized based on responses to the SF-36 general health and transition health items in order to compare groups differing in terms of health status.

\section{Results \\ Stage I qualitative interview results}

Twenty-three interviews were conducted during Stage I (16 in-person and seven telephone). The majority of subjects were female (57\%), aged $18-45$ years (52\%), and Caucasian (61\%). Mean BMI was $32.1 \mathrm{~kg} / \mathrm{m}^{2}$.

Respondents found the instructions, items, and response options in the DIAB-Q to be brief, yet comprehensive, clear, and easy to complete. The consistent use of a seven-point scale (ie, respondents had the same number of response choices for all items) facilitated selection of answers across questions; respondents did not express confusion even when the response options changed. Comments were provided, but they were not substantive enough to warrant modifications to the draft items. In general, respondents endorsed the concepts in the DIAB-Q as being relevant to their intentions to engage in diabetes-related self-care activities.

For the questions related to physical activity, instrument instructions broadly define exercise as including aerobic exercise, strength or resistance training, flexibility or stretching exercises, and activities of daily living (such as choosing to take the stairs instead of the elevator). When recording their survey answers, $35 \%$ of respondents indicated that they were thinking of exercise as a planned, purposeful, rigorous activity to raise heart rate and burn sugars, whereas $57 \%$ were thinking of exercise as day-to-day non-strenuous physical activity; $9 \%$ of respondents considered the term exercise to include both of these definitions. More than half of respondents (61\%) had agreed to engage in a specific exercise regimen to manage their T2DM based on recommendations from a doctor or other health care professional. Typical regimens included both rigorous and non-rigorous physical activities.

During the patient interviews that were to develop the DIAB-Q, it was observed that people with T2DM frequently used the term "diabetes diet" to describe their eating plans. Thus, the term "diabetes diet" was used in relevant items in the instrument and was defined as guidelines for food choices that reduce sugar and carbohydrate intake, focusing on both what to eat and what not to eat. Most respondents (91\%) indicated that they followed a specific diabetes diet. A small number of respondents commented that, for items related to their desire to follow a diabetes diet, they were uncertain how to define "desire" and how to accurately reflect differences between needing and wanting to follow a diabetes diet.

Interpretations of the questions related to weight loss and weight management were highly consistent and accurate. 
However, a few respondents reported difficulty accurately expressing whether their family, friends, or health care professionals expect them to lose weight because of the inclusion of three different types of people within the same question (eg, family and friends may have different expectations than health care providers).

\section{Stage II demographics}

For the online questionnaire, 1,015 respondents completed the baseline questionnaire, and 814 completed the retest questionnaire 3-7 days later. Demographic characteristics are summarized in Table 1.

Table I Demographic characteristics of the Stage II population

\begin{tabular}{|c|c|}
\hline Characteristics $(\mathrm{N}=1,0 \mid 5)$ & n (\%) \\
\hline \multicolumn{2}{|l|}{ Sex } \\
\hline Male & $604(60)$ \\
\hline Female & $4 I I(40)$ \\
\hline Age (mean \pm SD), $y$ & $63 \pm 11$ \\
\hline \multicolumn{2}{|l|}{ Race/ethnicity } \\
\hline Caucasian & $855(84)$ \\
\hline Black or African American & $44(4)$ \\
\hline Hispanic & $69(7)$ \\
\hline Other & $31(3)$ \\
\hline Decline to answer & $16(2)$ \\
\hline Married & $653(64)$ \\
\hline College educated & $467(46)$ \\
\hline \multicolumn{2}{|l|}{ Income } \\
\hline$<\$ 50,000$ & $390(38)$ \\
\hline$\$ 50,000-\$ 100,000$ & $318(31)$ \\
\hline$>\$ 100,000$ & $166(16)$ \\
\hline Declined to answer & $|4|(14)$ \\
\hline \multicolumn{2}{|l|}{ BMI, kg/m² } \\
\hline Normal $(<25)$ & $98(10)$ \\
\hline Overweight (25-29.9) & $317(31)$ \\
\hline Obese (30-39.9) & 498 (49) \\
\hline Extremely obese $(\geq 40)$ & $102(10)$ \\
\hline \multicolumn{2}{|l|}{ Antihyperglycemic treatment } \\
\hline Oral only & $651(64)$ \\
\hline Oral + insulin \pm non-insulin injectable & $176(17)$ \\
\hline Non-insulin injectable \pm oral or insulin & $67(7)$ \\
\hline Insulin only & $10 \mid(10)$ \\
\hline None & $20(2)$ \\
\hline Years since T2DM diagnosis (mean \pm SD) & $12 \pm 9$ \\
\hline \multicolumn{2}{|c|}{ Most commonly reported types of health care providers visited } \\
\hline \multicolumn{2}{|l|}{ in the past 12 months for T2DM care* } \\
\hline General practitioner & $871(86)$ \\
\hline Ophthalmologist & $351(35)$ \\
\hline Cardiologist & $197(19)$ \\
\hline Endocrinologist/diabetologist & $178(18)$ \\
\hline Podiatrist & $172(17)$ \\
\hline Nurse practitioner/physician assistant & $153(15)$ \\
\hline Diabetes nurse educator & $99(10)$ \\
\hline
\end{tabular}

Note: *Includes provider types visited by $\geq 10 \%$ of respondents in the past 12 months. Abbreviations: SD, standard deviation; T2DM, type 2 diabetes mellitus; $y$, years.

\section{Confirmatory factor analysis}

Fit indices for the initial DIAB-Q conceptual framework model indicated a poor fit (standards for establishing a good fit are in parentheses), suggesting that the data did not conform well to the conceptual model: CFI $(>0.90)=0.477$, TLI $(>0.90)=0.316$, RMSEA $(<0.06)=0.218$, and SRMR $(<0.08)=0.142$. Examination of modification indices suggested that items with similar content (ie, exercise $=$ items $1-6$, diet $=$ items $7-12$, and weight $=$ items $13-17$ ) were correlated. The CFA model was modified to allow correlated residuals between these items, which did not change the scoring of the instrument. With this modification, a good model fit was obtained: $\mathrm{CFI}=0.987$, TLI $=0.971$, RMSEA $=0.044$, and SRMR $=0.031$.

\section{Floor and ceiling effects}

The percentage of DIAB-Q construct scores at the lowest value (floor) ranged from $0 \%$ to $6 \%$, whereas the percentage at the highest value (ceiling) ranged from 3\% to 33\% (only one construct, PBC, exceeded 15\%).

\section{Internal consistency and test-retest reliability}

Internal consistency was determined based on Cronbach's alpha coefficients for all constructs using data from all respondents. Test-retest reliability scores based on ICCs were calculated for the 529 respondents who did not have a change in health status from baseline to retest 3-7 days later. Cronbach's alpha coefficients for the DIAB-Q constructs were 0.66 (Subjective Norm), 0.63 (Attitude), 0.68 (PBC), 0.46 (Intention), 0.61 (Planning), and 0.30 (Behavior). ICCs were as follows: 0.71 (Subjective Norm), 0.81 (Attitude), 0.63 (PBC), 0.78 (Intention), 0.83 (Planning), and 0.84 (Behavior).

\section{Construct validity}

Table 2 displays correlations between DIAB-Q psychological constructs and SF-36 physical component summary (PCS) and mental component summary (MCS), SDSCA items, and MDQ self-efficacy scores for the 1,015 respondents who completed initial surveys and for a sample consisting of 560 of the original respondents who could be contacted and were willing to complete the surveys again 1 year later. With few exceptions, correlations between DIAB-Q psychological constructs were more highly correlated with the diabetes-specific measures than the general measure. Divergent validity was assessed by examining the correlations between all DIAB-Q scales 
Table 2 Construct validity - correlations between the DIAB-Q and the collateral measures

\begin{tabular}{|c|c|c|c|c|c|}
\hline \multirow[t]{2}{*}{ DIAB-Q scale } & \multicolumn{2}{|c|}{ Baseline $(n=1,015)$} & \multicolumn{3}{|c|}{ I-year follow-up $(n=560)$} \\
\hline & SF-36 PCS & SF-36 MCS & SDSCA diet & SDSCA exercise & MDQ self-efficacy \\
\hline Subjective Norm & $0.177^{*}$ & $0.087 * *$ & $0.100 * * *$ & $0.192 *$ & $0.095 * * *$ \\
\hline Attitude & $0.169 *$ & 0.023 & $0.209 *$ & $0.250^{*}$ & $0.164^{*}$ \\
\hline Perceived Behavioral Control & $0.214^{*}$ & $0.160^{*}$ & 0.062 & 0.075 & 0.059 \\
\hline Intention & $0.202^{*}$ & $0.140 *$ & $0.295^{*}$ & $0.337 *$ & $0.342 *$ \\
\hline Planning & $0.228^{*}$ & $0.167^{*}$ & $0.33 I^{*}$ & $0.391 *$ & $0.389 *$ \\
\hline Behavior & $0.290 *$ & $0.201 *$ & $0.500 *$ & $0.498 *$ & $0.512 *$ \\
\hline
\end{tabular}

Notes: $* P<0.001$. $* * P<0.01$. $* * * P<0.05$.

Abbreviations: DIAB-Q, Diabetes Intention, Attitude, and Behavior Questionnaire; SF-36, Short Form-36 version 2 acute; PCS, physical component summary; MCS, mental component summary; SDSCA, Summary of Diabetes Self-Care Activities; MDQ, Multidimensional Diabetes Questionnaire.

and the SF-36 PCS and MCS scores; all were low (range: 0.02-0.29), indicating that these patient-reported outcome measures assess different constructs. Convergent validity analyses showed that all prespecified expected relationships between similar concepts were borne out and significantly correlated $(P<0.01$; Supplementary material).

\section{Known-groups validity}

Table 3 displays results for known-groups validity for Intention, Planning, and Behavior. Based on BMI categories, there were differences between groups on all three scales (all $P \leq 0.010$ ). In general, those with lower BMI reported higher scores (ie, greater engagement in health behaviors) than those with higher BMI. Based on separate analyses comparing $\mathrm{HbA}_{1 \mathrm{c}}$ and disease severity categories, there were significant differences between groups for Intention $(P<0.05)$, Planning $(P<0.001)$, and Behavior $(P<0.001)$, with those with less severe disease and lower $\mathrm{HbA}_{1 \mathrm{c}}$ levels showing greater engagement in healthy behaviors.

\section{Minimal clinically important change}

The MCICs ranged from 8-11 points for Subjective Norms, 6-9 points for Attitude, 6-9 points for PBC, 6-10 points for Intention, 6-11 points for Planning, and 7-12 points for Behavior (Supplementary material). These values allow an estimation of the amount of change for each scale that could be considered important to a respondent.

\section{Discussion}

The TPB is among the most widely used models for prediction of human behavior, ${ }^{28}$ however, there are no established questionnaires based on the TPB that are specific to diabetesrelated self-care behaviors. Therefore, the DIAB-Q was developed using TPB question stems to measure self-care behaviors of specific importance for individuals with T2DM. Results of the current study evaluated the content and clarity of the DIAB-Q and assessed the measurement properties of this TPB questionnaire.

The DIAB-Q items were developed based on input from health care professionals and patients, as well as from various literature sources. Validated instruments were also used as a guide in the development of content relevant to self-care behaviors that are important for patients with T2DM, including the SDSCA, ${ }^{17}$ SF-36 questionnaire, ${ }^{18}$ and MDQ. ${ }^{19}$ It is common to use item banks as a starting point rather than concept elicitation (eg, in the development of cancer qualityof-life measures by the European Organization for Research and Treatment of Cancer). ${ }^{29-31}$ The DIAB-Q framework was based largely on validated guidelines and specific question stems set forth by Ajzen for constructing a predictive questionnaire using the well-tested TPB. ${ }^{10}$

Participants for the current study were recruited from Harris Interactive and enrolled based on a self-reported diagnosis of T2DM. Our study was limited in that data were not collected for screen failures. In addition, Stage II respondents were not ethnically diverse ( $84 \%$ were Caucasian). It is important to note that the known-groups validity analysis was based on self-reported measures of body weight, disease severity, and $\mathrm{HbA}_{1 \mathrm{c}}$ levels. Different results may have been obtained if more objective measures were used (eg, if measures were provided by physicians instead of patient self-reports).

The TPB is a useful model for predicting health-related behavior, ${ }^{12}$ yet a full operationalization of the theory for just one behavior could involve 50 or more items. In studies where multiple measures are required, this may represent an unacceptable burden on participants and study staff. The DIAB-Q provides a 17-item operationalization that assesses TPB constructs, planning (physical activity, dietary behavior, and weight loss), and self-reports of physical activity and dietary behavior. Thus, the DIAB-Q could be a useful tool to distinguish between individuals who are likely or unlikely 
Table 3 Mean scale scores for DIAB-Q constructs by BMI category, HbA $\mathrm{Ic}_{\mathrm{c}}$ category, and disease severity

\begin{tabular}{|c|c|c|c|}
\hline Scale & $\mathbf{N}$ & Mean \pm SD $^{\S}$ & $P$-value for group differences \\
\hline \multicolumn{4}{|c|}{ BMI categories $\left(\mathrm{kg} / \mathrm{m}^{2}\right)(\mathrm{n}=1,015)$} \\
\hline \multicolumn{4}{|l|}{ Intention } \\
\hline$<25$ & 98 & $63.2 \pm 20.0^{\mathrm{a}}$ & 0.01 \\
\hline $25-29.9$ & 317 & $69.1 \pm 18.3^{b}$ & \\
\hline $30-39.9$ & 498 & $66.1 \pm 19.3^{\mathrm{a}, \mathrm{b}}$ & \\
\hline$\geq 40$ & 102 & $63.8 \pm 17.9^{\mathrm{a}}$ & \\
\hline \multicolumn{4}{|l|}{ Planning } \\
\hline$<25$ & 98 & $55.0 \pm 24.2^{\mathrm{a}}$ & 0.002 \\
\hline $25-29.9$ & 317 & $62.0 \pm 21.4^{b}$ & \\
\hline $30-39.9$ & 498 & $57.3 \pm 23.3^{\mathrm{a}, \mathrm{b}}$ & \\
\hline$\geq 40$ & 102 & $54.2 \pm 22.1^{\mathrm{a}}$ & \\
\hline \multicolumn{4}{|l|}{ Behavior } \\
\hline$<25$ & 98 & $63.0 \pm 24.8^{\mathrm{a}}$ & $<0.001$ \\
\hline $25-29.9$ & 317 & $56.8 \pm 23.2^{b}$ & \\
\hline $30-39.9$ & 498 & $47.4 \pm 23.9^{c}$ & \\
\hline$\geq 40$ & 102 & $41.7 \pm 24.8^{c}$ & \\
\hline \multicolumn{4}{|c|}{$\mathrm{HbA}_{\mathrm{Ic}}$ categories $(\%)(\mathrm{n}=82 \mathrm{I})$} \\
\hline \multicolumn{4}{|c|}{ Intention } \\
\hline$\leq 6.0$ & 130 & $71.5 \pm 19.2^{\mathrm{a}}$ & 0.001 \\
\hline $6.1-6.5$ & 211 & $67.9 \pm 18.5^{\mathrm{a}}$ & \\
\hline $6.6-7.0$ & 218 & $69.6 \pm 17.3^{\mathrm{a}}$ & \\
\hline $7.1-7.5$ & 147 & $65.8 \pm 18.2^{\mathrm{a}, \mathrm{b}}$ & \\
\hline $7.6-8.0$ & 51 & $64.5 \pm 20.3^{\mathrm{a}, \mathrm{b}}$ & \\
\hline$>8.0$ & 64 & $60.7 \pm 19.1^{b}$ & \\
\hline \multicolumn{4}{|l|}{ Planning } \\
\hline$\leq 6.0$ & 130 & $64.8 \pm 21.3^{\mathrm{a}}$ & $<0.001$ \\
\hline $6.1-6.5$ & 211 & $60.6 \pm 23.1^{a, b}$ & \\
\hline $6.6-7.0$ & 218 & $60.9 \pm 21.8^{\mathrm{a}, \mathrm{b}}$ & \\
\hline $7.1-7.5$ & 147 & $54.7 \pm 21.9^{\mathrm{b}, \mathrm{c}}$ & \\
\hline $7.6-8.0$ & 51 & $54.8 \pm 22.7^{b, c}$ & \\
\hline$>8.0$ & 64 & $50.8 \pm 22.2^{c}$ & \\
\hline \multicolumn{4}{|l|}{ Behavior } \\
\hline$\leq 6.0$ & 130 & $58.7 \pm 21.9^{a}$ & $<0.001$ \\
\hline $6.1-6.5$ & 211 & $53.8 \pm 23.0^{a, b}$ & \\
\hline $6.6-7.0$ & 218 & $55.6 \pm 23.8^{\mathrm{a}, \mathrm{b}}$ & \\
\hline $7.1-7.5$ & 147 & $48.1 \pm 24.9^{b, c}$ & \\
\hline $7.6-8.0$ & 51 & $41.3 \pm 24.3^{c, d}$ & \\
\hline$>8.0$ & 64 & $37.2 \pm 22.7^{d}$ & \\
\hline \multicolumn{4}{|c|}{ Disease severity $(n=1,0 \mid 5)$} \\
\hline \multicolumn{4}{|l|}{ Intention } \\
\hline Mild & 305 & $68.5 \pm 17.9^{\mathrm{a}}$ & 0.041 \\
\hline Moderate & 602 & $66.2 \pm 19.2^{\mathrm{a}, \mathrm{b}}$ & \\
\hline Severe & 61 & $62.2 \pm 22.3^{b}$ & \\
\hline \multicolumn{4}{|l|}{ Planning } \\
\hline Mild & 305 & $62.8 \pm 21.4^{\mathrm{a}}$ & $<0.001$ \\
\hline Moderate & 602 & $57.4 \pm 22.8^{\mathrm{a}}$ & \\
\hline Severe & 61 & $50.0 \pm 23.8^{\mathrm{b}}$ & \\
\hline \multicolumn{4}{|l|}{ Behavior } \\
\hline Mild & 305 & $56.6 \pm 23.5^{\mathrm{a}}$ & $<0.001$ \\
\hline Moderate & 602 & $50.2 \pm 24.3^{b}$ & \\
\hline Severe & 61 & $41.0 \pm 25.6^{c}$ & \\
\hline
\end{tabular}

Notes: Scale scores range from 0-100, with higher scores representing a higher level of the psychological construct. \$Mean values not sharing common superscripts are significantly different at $P<0.05$ based on Tukey's b post hoc. For example, under Behavior, the $<25$ group is significantly different from all other groups (no shared letter), whereas there are no differences between the 30-39.9 and $\geq 40$ groups (both share the letter " $\mathrm{c}$ ").

Abbreviations: DIAB-Q, Diabetes Intention, Attitude, and Behavior Questionnaire; BMl, body mass index; $\mathrm{HbA}_{\mathrm{I}}$, glycated hemoglobin; SD, standard deviation. 
to perform self-care behaviors related to diet, exercise, and weight management.

The American Diabetes Association Standards of Medical Care in Diabetes - 2015, as well as several other guidelines, ${ }^{1,32-34}$ identify adherence to self-care behaviors as an essential component of standard diabetes and prediabetes care that can significantly improve outcomes and reduce costs. ${ }^{1}$ Identification of gaps in patients' self-care attitudes and practices could allow health care providers to implement targeted, individualized diabetes self-management education, and support plans to help patients meet their medical needs, achieve their treatment goals, and have more positive life experiences. ${ }^{1}$

In the future, it would be informative to test the DIAB-Q with a more diverse population of individuals with T2DM. It would also be interesting to look at additional parameterizations that evaluate intensity and duration of exercise. The DIAB-Q includes items assessing the number of days respondents exercised in the past week using a broad definition of exercise in the instructions, but duration and intensity of exercise may also be important when considering intentions, attitudes, and behaviors relevant to diabetes self-management.

\section{Conclusion}

The DIAB-Q is a newly developed tool to evaluate intention to engage in self-care behaviors, such as following a diabetes diet and engaging in physical activity. Tracking patient norms, attitudes, and intentions related to diabetes self-care activities may help health care professionals identify optimal T2DM management approaches that incorporate individuals' beliefs and preferences to maximize adoption and long-term maintenance of healthy behaviors.

\section{Acknowledgments}

The work was partially funded by the UK National Institute for Health Research (NIHR) Collaboration for Leadership in Applied Health Research and Care of the South West Peninsula (PenCLAHRC), but the views expressed in this paper are those of the authors and not necessarily those of NIHR or the UK Department of Health. The authors would like to acknowledge the work of Jonathan Weiser for helping to develop the study materials and interpret the findings. Editorial assistance was provided by Cherie Koch, $\mathrm{PhD}$, of MedErgy and was funded by Janssen Global Services, LLC. This research was funded by Janssen Research \& Development, LLC, in part through a contract to Health Outcomes Solutions.

\section{Author contributions}

All authors contributed to the design and conduct of the research, drafting and/or providing critical input to the manuscript, and approved the final version for submission.

\section{Disclosure}

SBT is a full-time employee of Janssen Global Services, LLC. SDM is an employee of Health Outcomes Solutions, and HHC and RDC were paid consultants of Health Outcomes Solutions. CA has no relevant conflicts of interest to declare.

\section{References}

1. Inzucchi SE, Bergenstal RM, Buse JB, et al. Management of hyperglycemia in type 2 diabetes: a patient-centered approach. Position statement of the American Diabetes Association (ADA) and the European Association for the Study of Diabetes (EASD). Diabetes Care. 2012; 35(6):1364-1379.

2. Gregg EW, Gerzoff RB, Thompson TJ, Williamson DF. Trying to lose weight, losing weight, and 9-year mortality in overweight U.S. adults with diabetes. Diabetes Care. 2004;27(3):657-662.

3. Shigaki C, Kruse RL, Mehr D, et al. Motivation and diabetes selfmanagement. Chronic Illn. 2010;6(3):202-214.

4. Pi-Sunyer FX. The impact of weight gain on motivation, compliance, and metabolic control in patients with type 2 diabetes mellitus. Postgrad Med. 2009;121(5):94-107.

5. Wadden TA, Neiberg RH, Wing RR, et al. Four-year weight losses in the Look AHEAD study: factors associated with long-term success Obesity (Silver Spring). 2011;19(10):1987-1998.

6. Abraham C, Sheeran P, Johnston M. From health beliefs to selfregulation: theoretical advances in the psychology of action control Psychol Health. 1998;13(4):569-591.

7. Bandura A. Health promotion from the perspective of social cognitive theory. Psychol Health. 1998;13:623-649.

8. Abraham C, Sheeran P, Norman P, Conner M, De Vries N, Otten W. When good intentions are not enough: modeling postdecisional cognitive correlates of condom use. J Appl Soc Psychol. 1999;29(12):2591-2612.

9. Schwarzer R. Modeling health behavior change: how to predict and modify the adoption and maintenance of health behaviors. Appl Psychol. 2008; 57(1):1-29.

10. Ajzen I. Constructing a Theory of Planned Behavior Questionnaire. Available from: http://people.umass.edu/aizen/pdf/tpb.measurement. pdf. Accessed November 14, 2014.

11. Ajzen I. The theory of planned behavior. Organ Behav Hum Decis Process. 1991;50:179-211.

12. McEachan RRC, Conner M, Taylor NJ, Lawton RJ. Prospective prediction of health-related behaviours with the theory of planned behaviour: a meta-analysis. Health Psychol Rev. 2011;5(2):97-144.

13. Hagger MS, Chatzisarantis NLD, Biddle SJH. A meta-analytic review of the theories of reasoned action and planned behaviour in physical activity: predictive validity and the contribution of additional variables. J Sport Exerc Psychol. 2002;24(1):3-32.

14. Webb TL, Sheeran P. Does changing behavioral intentions engender behavior change? A meta-analysis of the experimental evidence. Psychol Bull. 2006;132(2):249-268.

15. Jones F, Abraham C, Harris P, Schulz J, Chrispin C. From knowledge to action regulation: modeling the cognitive prerequisites of sunscreen use in Australian and UK samples. Psychol Health. 2001;16(2): 191-206.

16. Rosenstock J, Aggarwal N, Polidori D, et al. Dose-ranging effects of canagliflozin, a sodium-glucose cotransporter 2 inhibitor, as add-on to metformin in subjects with type 2 diabetes. Diabetes Care. 2012; $35(6): 1232-1238$ 
17. Toobert DJ, Hampson SE, Glasgow RE. The summary of diabetes self-care activities measure: results from 7 studies and a revised scale. Diabetes Care. 2000;23(7):943-950.

18. Ware JE, Kosinski M, Dewey JE. How to Score Version 2 of the SF-36 Health Survey. Lincoln, RI: QualityMetric Incorporated, 2000.

19. Talbot F, Nouwen A, Gingras J, Gosselin M, Audet J. The assessment of diabetes-related cognitive and social factors: the Multidimensional Diabetes Questionnaire. J Behav Med. 1997;20:291-312.

20. Hu L, Bentler PM. Cutoff criteria for fit indexes in covariance structure analysis: conventional criteria versus new alternatives. Struct Equ Modeling. 1999;6(1):1-55.

21. Muthen LK, Muthen BO. Mplus Users Guide. 3rd ed. Los Angeles, CA: Muthen \& Muthen; 2004.

22. Terwee CB, Bot SD, de Boer MR, et al. Quality criteria were proposed for measurement properties of health status questionnaires. J Clin Epidemiol. 2007;60(1):34-42.

23. Cronbach L. Coefficient alpha and the internal structure of tests. Psychometrika. 1951;16(3):297-333.

24. Lohr KN, Aaronson NK, Alonso J, et al. Evaluating quality-of-life and health status instruments: development of scientific review criteria. Clin Ther. 1996;18(5):979-992.

25. National Institutes of Health. Clinical guidelines on the identification, evaluation, and treatment of overweight and obesity in adults: the evidence report. Obes Res. 1998;6(suppl 2):51S-209S.

26. Winer BJ. Statistical Principles in Experimental Design. 2nd ed. New York, NY: McGraw-Hill; 1971:1-907.
27. Crosby RD, Kolotkin RL, Williams GR. Defining clinically meaningful change in health-related quality of life. J Clin Epidemiol. 2003;56(5): 395-407.

28. Ajzen I. The theory of planned behaviour: reactions and reflections. Psychol Health. 2011;26(9):1113-1127.

29. Gamper EM, Groenvold M, Petersen MA, et al. The EORTC emotional functioning computerized adaptive test: phases I-III of a cross-cultural item bank development. Psychooncology. 2014;23(4):397-403.

30. Bottomley A, Vachalec S, Bjordal K, Blazeby J, Flechtner H, Ruyskart P. The development and utilisation of the European Organisation for research and treatment of cancer quality of life group item bank. Eur J Cancer. 2002;38(12):1611-1614.

31. Giesinger JM, Petersen MA, Groenvold M, et al. Cross-cultural development of an item list for computer-adaptive testing of fatigue in oncological patients. Health Qual Life Outcomes. 2011;9:19.

32. American Diabetes Association. Standards of medical care in diabetes2015. Diabetes Care. 2015;38(suppl):S1-S93.

33. National Collaborating Centre for Chronic Conditions (UK). Type 2 Diabetes: National Clinical Guideline for Management in Primary and Secondary Care (Update). London, UK: Royal College of Physicians (UK); 2008.

34. American Association of Diabetes Educators Position Statement. AADE7 Self-Care Behaviors. Diabetes Educ. 2008;34(3):445-449.
Patient Preference and Adherence

\section{Publish your work in this journal}

Patient Preference and Adherence is an international, peer-reviewed, open access journal that focuses on the growing importance of patient preference and adherence throughout the therapeutic continuum. Patient satisfaction, acceptability, quality of life, compliance, persistence and their role in developing new therapeutic modalities and compounds to optimize

\section{Dovepress}

clinical outcomes for existing disease states are major areas of interest for the journal. This journal has been accepted for indexing on PubMed Central. The manuscript management system is completely online and includes a very quick and fair peer-review system, which is all easy to use. Visit http://www. dovepress.com/testimonials.php to read real quotes from published authors. 